\title{
A Comparison of the Segmental Analysis of Sodium Reabsorption during Ringer's and Hyperoncotic Albumin Infusion in the Rat
}

\author{
Jay H. Stein, Richard W. Osgood, Sampanta Boonjarern, and \\ THOMAS F. FERRIS \\ From the Department of Medicine, Ohio State University, \\ Columbus, Ohio 43210
}

A в S T R A C T Studies were designed to compare the segmental analysis of sodium reabsorption along the nephron during volume expansion with either $10 \%$ body weight Ringer's or $0.6 \%$ body weight hyperoncotic albumin. Total kidney and nephron glomerular filtration rate increased similarly with both, but urinary sodium excretion (12.7 vs. $4.0 \mu \mathrm{eq} / \mathrm{min}, P<0.001)$ and fractional sodium excretion ( 5.0 vs. $1.6 \%, P<0.001)$ increased to a greater extent with Ringer's. Fractional reabsorption of sodium in the proximal tubule was diminished in both groups but to a significantly greater extent during Ringer's $(P<0.005)$. Absolute reabsorption was inhibited only in the Ringer's group. Delivery of filtrate out of the proximal tubule was greater in the Ringer's studies, 45 vs. $37 \mathrm{nl} / \mathrm{min}(P<0.001)$. However, both fractional and absolute sodium delivery to the early and late distal tubule were not significantly different in the two groups. Fractional reabsorption in the collecting duct decreased from $96 \%$ in hydropenia to $31 \%$ during Ringer's but fell only slightly to $80 \%$ in the albumin studies. Absolute collecting duct reabsorption was also greater in the albumin studies, 0.55 vs. 0.21 neq/min $(P<0.001)$, which could totally account for the difference in urinary sodium excretion between the two groups. ${ }^{22} \mathrm{Na}$ recovery in the final urine after end distal microinjections was $71 \%$ during Ringer's infusion and $34 \%$ during albumin $(P<0.001)$. From these data we conclude that: $(a)$ Ringer's solution has a greater inhibitory effect on proximal tubular sodium reabsorption, and $(b)$ in spite of this effect, differences in mucosal to serosal collecting duct sodium transport are primarily responsible for the greater natriuresis during Ringer's infusion.

Received for publication 18 January 1973 and in revised form 27 April 1973.

\section{INTRODUCTION}

The nephron site responsible for the natriuresis which occurs during expansion of extracellular fluid volume with isotonic saline is not clear. Saline loading depresses proximal tubular sodium reabsorption and increases delivery of filtrate to more distal nephron sites $(1,2)$. Therefore, increased delivery of filtrate out of the proximal tubule might be primarily responsible for the natriuresis. However, several experimental models have demonstrated inhibition of proximal sodium reabsorption with only a minimal change in urinary sodium excretion (3-5). In addition, it has been found in dogs with sodium retention that proximal tubular sodium reabsorption is not different from that in normal animals either during hydropenia or saline loading despite marked differences in urinary sodium excretion (6-8). This data would suggest that delivery out of the proximal tubule may not be the major determinant of urinary sodium excretion.

To further evaluate this problem, a comparison was made of the segmental analysis of sodium reabsorption between rats given Ringer's solution and hyperoncotic albumin, a model known to lead to inhibition of proximal sodium reabsorption but with little change in urinary sodium excretion (3). The results suggest that the difference in sodium excretion in these two models is primarily due to alterations in sodium transport in the collecting duct.

\section{METHODS}

Studies were performed on male Sprague-Dawley rats weighing 290-380 g, which were allowed free access to water and a standard rat pellet diet. They were anesthetized with Inactin $(100 \mathrm{mg} / \mathrm{kg}$; Promonta, Hamburg, West Germany). Polyethylene catheters were inserted in both jugular veins for infusion and administration of lissamine 
TABLE I

Comparison of Early and Late D)istal Tubular Potassium and Inulin Ratios during Hydropenia

\begin{tabular}{|c|c|c|c|c|}
\hline \multirow[b]{2}{*}{ Fixp. no. } & \multicolumn{2}{|c|}{$(\mathrm{TF} / \mathrm{P})_{\mathrm{K}}$} & \multicolumn{2}{|c|}{$(\mathrm{TF}, \mathrm{P}){ }_{1 .}$} \\
\hline & Early & Late & Early & Late \\
\hline 1 & $\begin{array}{c}0.58 \\
(3)^{*}\end{array}$ & $\begin{array}{c}2.80 \\
(3)\end{array}$ & 6.47 & 17.32 \\
\hline 2 & $\begin{array}{c}0.36 \\
(3)\end{array}$ & $\begin{array}{c}2.16 \\
(4)\end{array}$ & 5.41 & 9.88 \\
\hline 3 & $\begin{array}{c}0.60 \\
(2)\end{array}$ & $\begin{array}{c}2.77 \\
(4)\end{array}$ & 4.95 & 13.12 \\
\hline 4 & $\begin{array}{c}0.52 \\
(3)\end{array}$ & $\begin{array}{l}3.04 \\
(2)\end{array}$ & 5.26 & 15.15 \\
\hline
\end{tabular}

* Number of observations.

green and in the femoral artery for withdrawal of blood and blood pressure monitoring. A tracheostomy was performed. A small left subcostal incision was made and the left kidney was gently separated from the adrenal gland and contiguous perirenal fat. In the majority of the studies, the left ureter was catheterized with $\mathrm{PE} 50$ tubing near the renal pelvis while urine from the right kidney was collected via a bladder catheter. There was no significant difference in glomerular filtration rate (GFR), ${ }^{1}$ urine flow, or sodium excretion between the two sides. In a few studies, urine was obtained only from a PE 50 bladder catheter. This was done because of the observation of Cortell and associates that ureteral catheterization, at least with $\mathrm{PE}$ 10 tubing, may increase intratubular pressure (9). However, as noted, there was no difference in the clearance data from the two kidneys when only the left ureter was catheterized. Additionally, the experimental data obtained were indistinguishable whether the left ureter was catheterized or not. Therefore, as also pointed out by the data of Cortell, Davidman, Gennari, and Schwartz (9), PE 50 tubing does not significantly alter outflow resistance.

The animal was placed on a thermoregulated heating board and the kidney was placed in a plexiglass holder. The surface was illuminated with a fiberoptic light source and the kidney was bathed with mineral oil at $37^{\circ} \mathrm{C}$. If the rat had a proximal tubular transit time greater than $13 \mathrm{~s}$ or undue retention of the dye in the distal tubule, the rat was not used.

The animal was initially given $0.5 \mathrm{ml}$ of a $10 \%$ inulin solution dissolved in Ringer's, and then a maintenance infusion at a rate of $0.02 \mathrm{ml} / \mathrm{min}$. While the inulin was equilibrating, late proximal and various distal tubular segments were localized with two to three injections of lissamine green $(0.05 \mathrm{ml}$ of a $10 \%$ solution). No puncture was obtained until at least $30 \mathrm{~min}$ after the last lissamine green injection. $1 \mathrm{~h}$ after the inulin infusion had been started, initial samples were collected.

The tubules were punctured with sharpened pipettes with tip diameters varying from 8 to $11 \mu \mathrm{m}$ for proximal tubular

\footnotetext{
${ }^{1}$ Abbreviations used in this paper: GFR, glomerular filtration rate; $(\mathrm{TF} / \mathrm{P})_{I n, \mathrm{sa}, \mathrm{k}}$, tubular fluid to plasma inulin, sodium, and potassium ratios, respectively; $V_{F}$, tubular flow rate; $V_{o}$, nephron filtration rate. Subscripts: ED, early distal tubule; $L D$, late distal tubule; Prox, proximal tubule.
}

collections and 5 to $7 \mu \mathrm{m}$ for distal tubular samples. After puncture, a large column of mineral oil stained with Sudan black was injected into the tubule. After initial gentle aspiration to begin the collection, most of the samples were collected either spontaneously or with only occasional aspiration to maintain the oil column in a constant position. All tubular fluid collections were timed.

The following studies were performed.

Control studies. To determine the reproducibility of the various parameters of segmental analysis, collection and recollection were obtained from proximal and distal tubules. In eight rats, proximal and distal recollection pairs were obtained during either hydropenia, Ringer's infusion, or hyperoncotic albumin administration given in the manner described below. In all cases, the recollection sample was obtained within $2 \mathrm{~min}$ of completion of the first puncture.

Ringer's infusions. 16 studies were performed in which collections were obtained before and during the infusion of Ringer's solution. In the first group of eight studies (group A), collections were initially obtained from end proximal and late distal tubular sites of collection during hydropenia. In these distal samples, only a segment which appeared in the last $25 \%$ of the transit of lissamine green through the distal convolution was utilized. Using this technique, the mean tubular fluid to plasma potassium ratio $\left[(\mathrm{TF} / \mathrm{P})_{\mathrm{K}}\right]$ during hydropenia was 2.42 , a value comparable with results previously found in late distal samples (10). In addition, in each of seven microdissections, the site of puncture was found to be in the last $25 \%$ of the distal tubule. After the completion of the control collections, $10 \%$ body weight Ringer's infusion was given over a period of approximately $50 \mathrm{~min}$. At the completion of the infusion, recollection samples were obtained from the previously punctured tubules while urinary losses were replaced with an equivalent amount of Ringer's solution.

In a second group of eight experiments (group B), only end-proximal tubular samples were collected during hydropenia. Then Ringer's was given in the same manner as in the group A studies. At the conclusion of the infusion, samples were collected from early and late distal tubular sites as well as from the previously punctured proximal tubules. The early and late distal tubules had been localized with lissamine green prior to the control period. To demonstrate that early and late segments could be differentiated by this method, four experiments were performed in which early and late tubular fluid to plasma inulin ratio $\left[(\mathrm{TF} / \mathrm{P})_{I_{n}}\right]$ and $\mathrm{TF} / \mathrm{P}_{\mathrm{K}}$ were determined from these sites during hydropenia. As is shown in Table $I$, there was a marked increase in both of these parameters in each of these four studies from early to late segments, a finding that is in agreement with previous results utilizing tubular dissection techniques to determine localization (10).

Hyperoncotic albumin studies. 15 of these studies were performed. In the first group of eight experiments (group A), late proximal and late distal tubules were marked and samples were collected as described in the group A Ringer's studies. These distal samples had a mean $T F / P_{K}$ ratio of 2.31 during hydropenia. At the completion of the first period, 25\% albumin (Hylan 1 Div., Travenol Laboratories, Cosa Mesa, Calif.), $0.6 \%$ body weight, was given over $35 \mathrm{~min}$. At the completion of the infusion, an equilibration period of approximately $15 \mathrm{~min}$ elapsed before obtaining repeat collections. During the equilibration and collection period, urinary losses were replaced.

In a second group of seven studies (group B), only end-proximal samples were collected in the control period. 
Then hyperoncotic albumin was given in the same manner as in the group A studies. After the equilibration period, samples were collected from early and late distal segments as well as the previously punctured proximal segments.

In each of these studies, blood was obtained at the beginning and end of a given period for inulin determination. Blood samples were also obtained in each experimental period for hematocrit determination and in some studies for serum protein analysis. The clearance data presented is the mean of two or more $10-12$ min collections. In the studies in which only the bladder was utilized for urine collection, the clearance data obtained was divided by 2 .

Microinjection studies. To further define collecting duct transport during Ringer's and hyperoncotic albumin infusion, end distal microinjection studies were performed. A carrierfree solution of ${ }^{22} \mathrm{Na}(150 \mu \mathrm{Ci} / \mu \mathrm{g}$; Radiochemical Centre, Amersham, England) was mixed with $\left[{ }^{3} \mathrm{H}\right]$ inulin in (100 $\mu \mathrm{Ci} / \mathrm{mg}$; New England Nuclear Corp., Boston, Mass.) dissolved in $\mathrm{H}_{2} \mathrm{O}$ and a small amount of F.D. \& C. Green dye number 311 (Keystone Aniline \& Chemical Co., Chicago, IIl.) was added to color the solution. The sodium concentration of this solution was less than $3 \mathrm{meq} / \mathrm{liter}$. This essentially carrier-free solution was utilized because of the work of Cortney which suggested that the injection of a significant quantity of carrier $\mathrm{Na}$ may alter collecting duct sodium transport (11). He found that end distal microinjection of ${ }^{22} \mathrm{Na}$ in isotonic saline had a very high urinary recovery when compared with a carrier-free microinjection. In addition, only the carrier-free injections correlated with end-distal and urinary sodium to inulin ratios (11).

Since it seemed preferable to inject a true tracer amount of $\mathrm{Na}$, a carrier-free solution was utilized in all studies. A number of droplets of constant volume $(2 \mathrm{nl})$ were obtained from a stock solution of the injectate mixture and placed under oil on the bottom of a small glass dish. The droplets were then either drawn into micropipettes for injection or directly evacuated into a scintillation vial for calibration of the amount of radioactivity given. The coefficient of variation of 12 replicate samples was $2 \%$. 15 injections were performed in nine Ringer's studies, while 12 injections were obtained in 10 albumin experiments performed in the same manner as described above. The $2 \mathrm{nl}$ colored solution was slowly injected into a late distal segment over approximately $30 \mathrm{~s}$ with care taken to avoid retrograde flow of the injectate. Left ureteral urine was collected directly into a scintillation vial containing $10 \mathrm{ml}$ of Aquasol (New England Nuclear Corp., Boston, Mass.). In the initial studies 8-10 consecutive vials were collected over a 5-10 min period to determine whether delayed recovery of ${ }^{22} \mathrm{Na}$ was present. In five Ringer's and five albumin injections, no evidence of a delayed appearance of ${ }^{22} \mathrm{Na}$ was noted, confirming the results of Gottschalk, Morel, and Mylle (12), who found no delayed recovery of sodium during either a mannitol or saline diuresis. In the remaining injections, two $5 \mathrm{~min}$ collections were obtained to determine nuclide recovery. No radioactivity was noted from the contralateral kidney when $\left[{ }^{3} \mathrm{H}\right]$ inulin recovery was $90 \%$ or greater. ${ }^{22} \mathrm{Na}$ and $\left[{ }^{8} \mathrm{H}\right]$ inulin were counted in a Packard Tri-Carb Liquid Scintillation spectrophotometer (Packard Instrument Co., Downers Grove, I11.). Appropriate correction was made for the crossover of ${ }^{22} \mathrm{Na}$ into the ${ }^{3} \mathrm{H}$ channel. Quench correction was performed with internal standardization. Only injections with a $\left[{ }^{3} \mathrm{H}\right]$ inulin recovery of greater than $90 \%$ were utilized.

Percent recovery of each nuclide was calculated with the formula: total nuclide in urine/total nuclide injected.
Plasma and urine inulin concentrations were determined by the anthrone method (13) while the concentration of inulin in tubular fluid was measured by the method of Vurek and Pegram (14). Tubular fluid volume was measured in a constant bore capillary of known internal diameter. Sodium and potassium concentration in distal tubular fluid was measured with an Aminco Helium Glow flame photometer (American Instrument Co., Inc., Silver Spring, Md.) and in urine and plasma with an Instrumentation Laboratory Flame Photometer (Instrumentation Laboratory, Inc., Watertown, Mass.). Serum protein concentration was determined by the Lowry method (15).

The data was analyzed by standard statistical methods and all results are presented as the mean \pm SEM.

Calculations. (1) Nephron filtration rate $\left(V_{0}\right)=(\mathrm{TF} /$ $\mathrm{P})_{I_{n}} \times\left(V_{\boldsymbol{F}}\right)$ where $(\mathrm{TF} / \mathrm{P})_{I_{n}}$ is the tubular fluid to plasma inulin ratio and $V_{F}$ equals the tubular flow rate in nanoliters per minute.

(2) Absolute reabsorption of filtrate in proximal tubule (Prox) in nanoliters per minute $=V_{0}-V_{F}$.

(3) Fractional reabsorption in proximal tubule (\%) $=1$ $-(\mathrm{P} / \mathrm{TF})_{\text {InProx }} \times 100$.

(4) Fractional reabsorption of sodium in Henle's loop $=$

$$
\frac{(\mathrm{P} / \mathrm{TF})_{\text {In Prox }_{\text {P }}}-(\mathrm{TF} / \mathrm{P})_{\mathrm{Na}} / \operatorname{In}_{E D}}{(\mathrm{P} / \mathrm{TF})_{\text {In Prox }}} \times 100
$$

where $(T F / P)_{x a} / I_{E D}$ is the tubular fluid to plasma sodium to inulin ratio in the early distal tubule.

(5) Fractional reabsorption of sodium in distal tubule $=$

$$
\frac{(\mathrm{TF} / \mathrm{P})_{\mathrm{Na}} / I n_{E D}-(\mathrm{TF} / \mathrm{P})_{\mathrm{Na}} / I n_{L D}}{(\mathrm{TF} / \mathrm{P})_{\mathrm{Na}} / I n_{E D}} \times 100
$$

where $(\mathrm{TF} / \mathrm{P})_{\mathrm{xa}_{\mathrm{a}}} / I_{n_{L D}}$ is the tubular fluid to plasma sodium to inulin ratio in late distal tubular fluid.

(6) Fractional reabsorption of sodium in Henle's loop and distal tubule $=$

$$
\frac{(\mathrm{P} / \mathrm{TF})_{\text {In Prox }}-(\mathrm{TF} / \mathrm{P})_{\mathrm{Na}} / I_{L D}}{(\mathrm{P} / \mathrm{TF})_{\text {In } n_{\text {Prox }}}} \times 100 .
$$

(7) Fractional reabsorption of sodium in collecting duct $=$

$$
1-\frac{F E_{\mathrm{Na}}}{(\mathrm{TF} / \mathrm{P})_{\mathrm{Na}} / I n_{L D}} \times 100
$$

where $F E_{\mathrm{Na}}$ is the fractional sodium excretion.

Absolute reabsorption in each nephron segment was calculated from the fractional reabsorption data and the nephron GFR. In 16 studies during hydropenia, 16 Ringer's and 15 albumin studies, the ratio of proximal to distal nephron GFR was $1.05,1.02$, and 1.04 , respectively, all values not different from 1 . Although values obtained from proximal samples were used to calculate absolute reabsorption in various nephron segments, similar data was obtained utilizing either distal values or the mean of both nephron GFR's.

\section{RESULTS}

Control studies. 18 proximal tubule recollection pairs were obtained, 5 during hydropenia and 13 during expansion. The mean $T F / \mathrm{P}_{\text {In }}$ first collection/TF/ $\mathrm{P}_{\text {In }}$ second collection ratio was $1.00 \pm 0.02$. The ratio of the nephron GFR and tubular flow rate in the first vs. sec- 


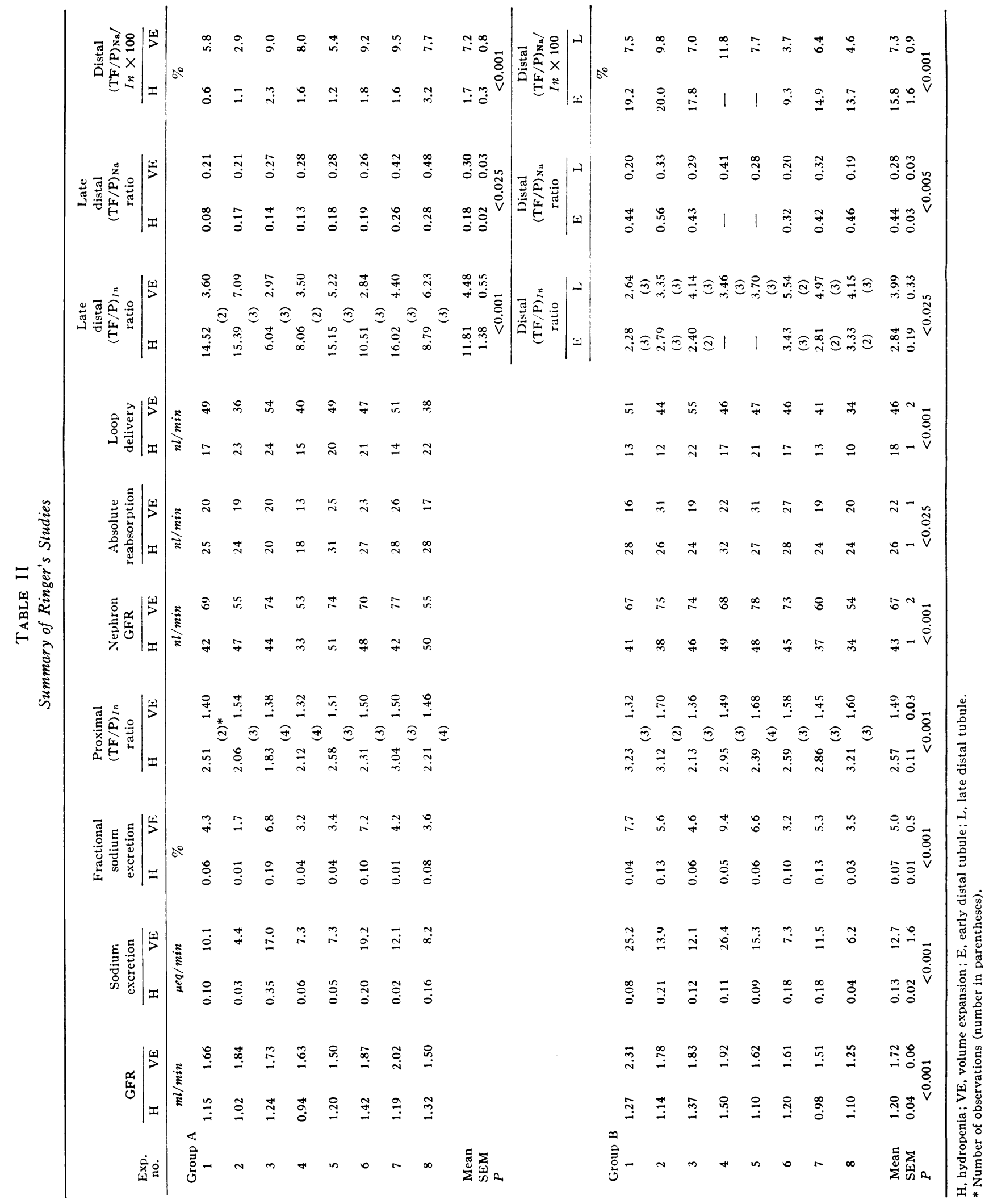


ond collection was $1.02 \pm 0.02$ and $1.00 \pm 0.03$. As can be noted from Fig. 1, there was some variation in the tubular flow rate in the recollection pairs, but the mean cofficient of variation of the flow rate out of the proximal tubule in the 18 recollection pairs was $9 \%$.

15 recollection pairs were obtained from the distal tubule during expansion. The mean ratio of both the distal (TFP) In first collection/(TF/P) In second collection and the $(\mathrm{TF} / \mathrm{P})_{\mathrm{Na}}$ ratio in the recollection pairs was $0.97 \pm 0.03$, while the nephron GFR ratio was $1.04 \pm$ 0.05. As is shown in Fig. 2, there was little scatter in the $(\mathrm{TF} / \mathrm{P})_{\mathrm{Na} / \mathrm{In}}$ ratio in the 15 recollection pairs with a coefficient of variation of $8 \%$.

Ringer's studies. The results of these studies are summarized in Table II. In these experiments, there was a mean decrease in arterial hematocrit from 47 to $39 \mathrm{ml} /$ $100 \mathrm{ml}$ while plasma protein concentration decreased from 6.7 to $5.1 \mathrm{~g} / 100 \mathrm{ml}$ during expansion. Total kidney GFR increased from 1.20 to $1.72 \mathrm{ml} / \mathrm{min}$, an increase of $43 \%$, while superficial nephron GFR increased $55 \%$ from 43 to $67 \mathrm{nl} / \mathrm{min}$. Although nephron GFR increased to a greater extent than kidney GFR in 11 of the 16 studies, the changes in nephron and kidney GFR were not significantly different for the entire group. Urinary sodium excretion increased from 0.13 to 12.7 $\mu \mathrm{eq} / \mathrm{min}$ while fractional sodium excretion increased from 0.07 to $5.0 \%$. There was a marked fall in the $(\mathrm{TF} / \mathrm{P})_{\text {In }}$ ratio in the proximal tubule from 2.57 to $1.49(P<0.001)$, a fall in absolute reabsorption of filtrate from 25.9 to $21.8 \mathrm{nl} / \mathrm{min}(P<0.025)$, and a rise in delivery of filtrate out of the proximal tubule of 28 $\mathrm{nl} / \mathrm{min}(P<0.001)$. As can be noted from the group A studies, in comparison with hydropenia there was a consistent decrease in the distal $(\mathrm{TF} / \mathrm{P})_{\text {In }}$ ratio in association with a rise in the $(\mathrm{TF} / \mathrm{P})_{\mathrm{s}}$ and $(\mathrm{TF} / \mathrm{P})_{\mathrm{n} / / n}$ values during volume expansion with Ringer's. In these studies, the fraction of sodium remaining at the end of the distal tubule increased from 1.7 to $7.2 \%(P<0.001)$. In addition, in the group B studies 15.8 and $7.3 \%$ of the filtered sodium remained at the early and late distal segment respectively.

Albumin studies. The results of these studies are summarized in Table III. Arterial hematocrit decreased from 47 to $37 \mathrm{ml} / 100 \mathrm{ml}$, a change not significantly different from that in the Ringer's studies. However, in contrast to the Ringer's studies, there was no significant change in the serum protein concentration during the experimental period. Total GFR increased from 1.22 to $1.74 \mathrm{ml} / \mathrm{min}$, an increase of $43 \%$ while superficial nephron GFR rose from 43 to $63 \mathrm{nl} / \mathrm{min}$, a $47 \%$ change. There was no significant difference in the increase in kidney and nephron GFR during albumin infusion. Sodium excretion and fractional sodium excretion rose to only $4.0 \mu \mathrm{eq} / \mathrm{min}$ and $1.6 \%$, respectively. The $(\mathrm{TF} / \mathrm{P})_{\mathrm{In}}$

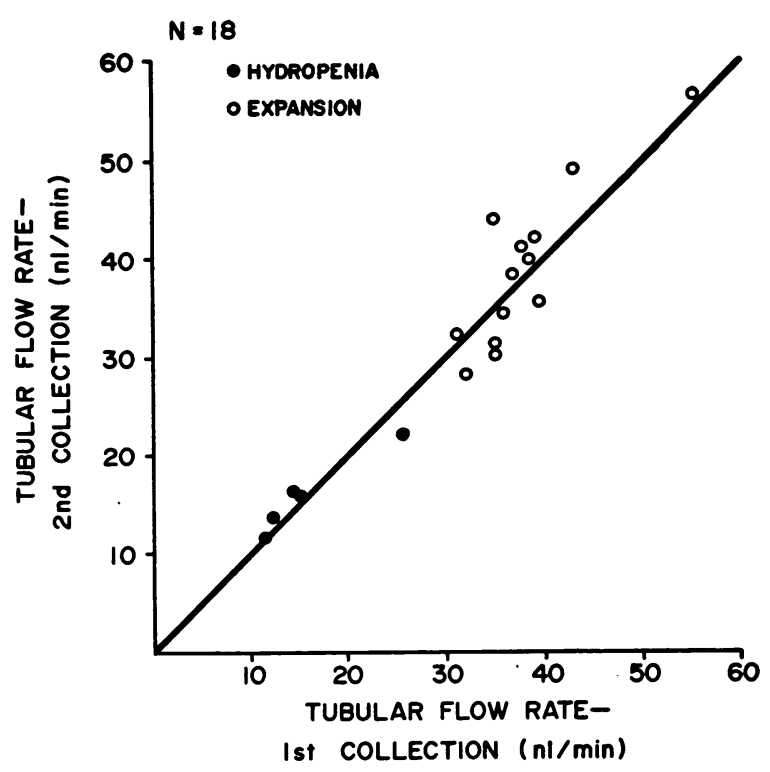

FIgLRE 1 Reproducibility of delivery of filtrate out of the proximal tubule using the recollection technique.

ratio in the proximal tubule also fell in this group with a mean change from 2.60 to $1.72(P<0.001)$ while delivery of filtrate out of the proximal tubule rose from 17 to $37 \mathrm{nl} / \mathrm{min}(P<0.001)$. There was no change in absolute reabsorption of filtrate in the proximal tubule in the albumin studies. In the group A studies, the amount of $\mathrm{Na}$ remaining at the end of the distal tubule increased

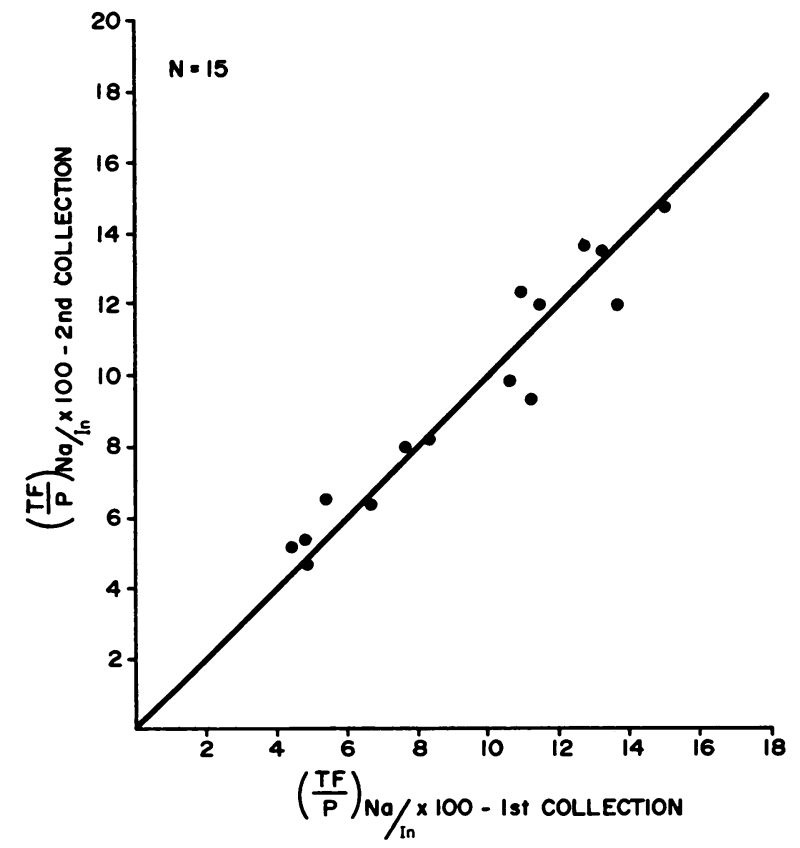

FIGURE 2 Reproducibility of delivery of sodium to the distal tubule using the recollection technique. 


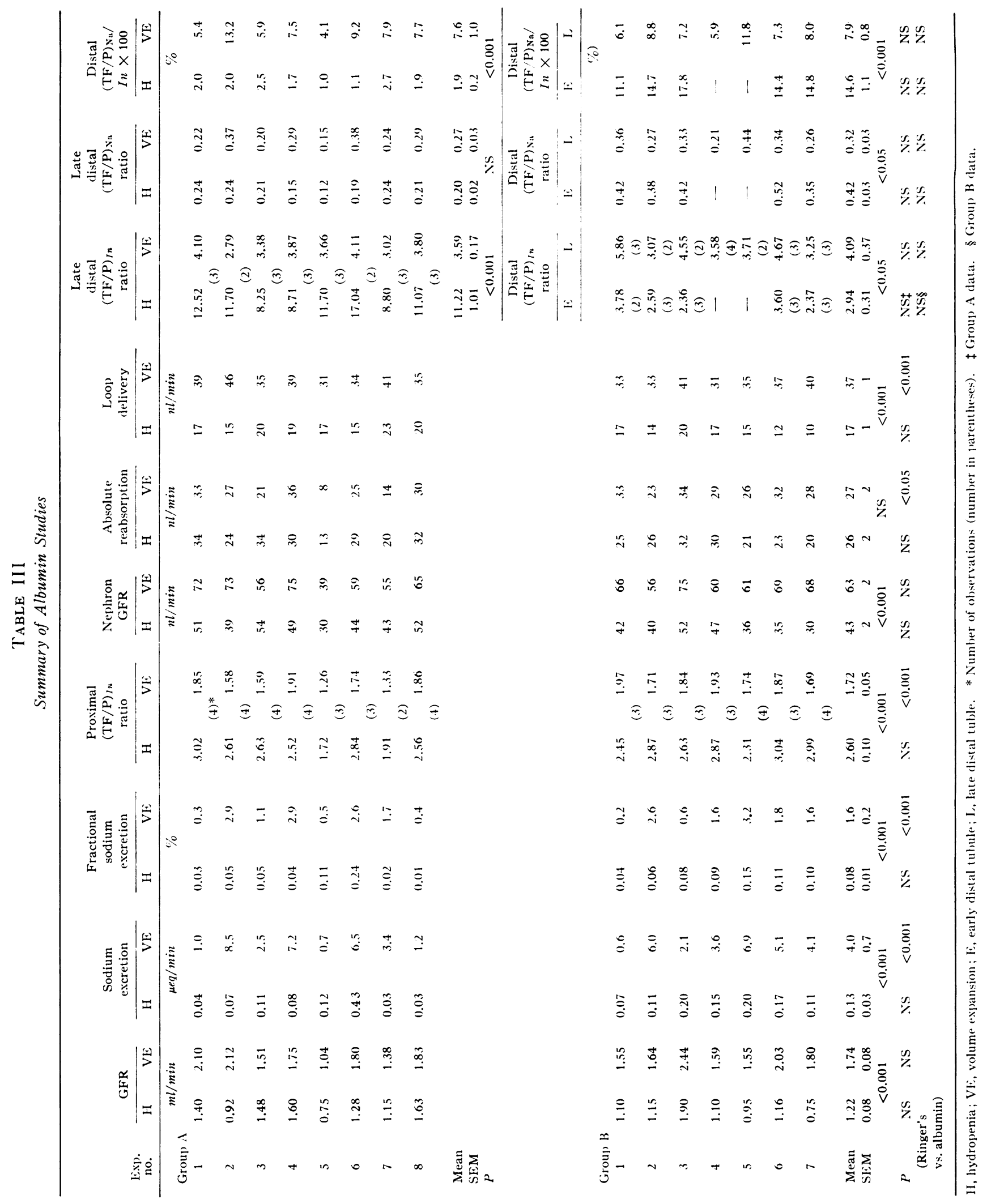




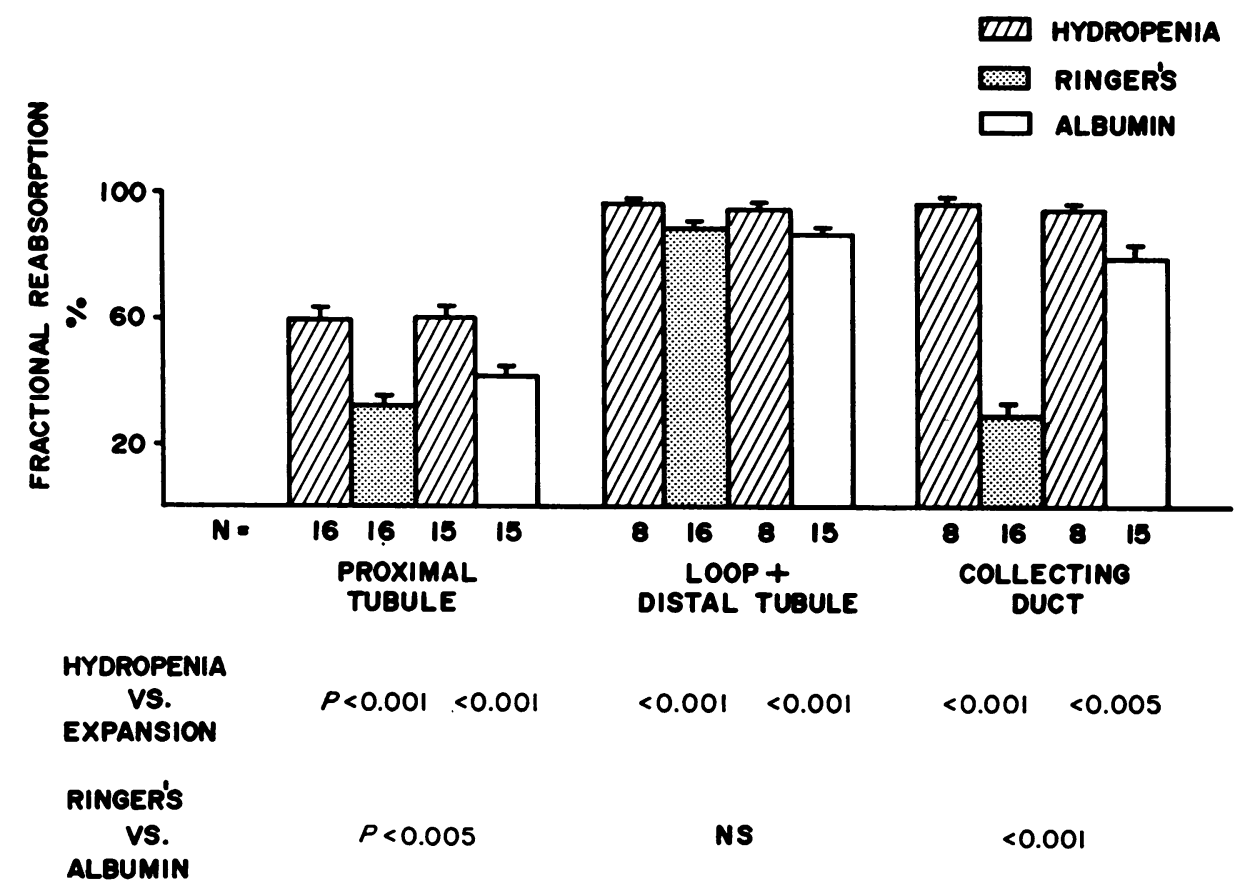

Figure 3 Segmental analysis of fractional sodium reabsorption during hydropenia, Ringer's, and hyperoncotic albumin infusion.

from $1.9 \%$ in hydropenia to $7.6 \%$ during albumin infusion. In the group B studies, $14.6 \%$ of the filtered load remained in the early distal segment while there was $7.9 \%$ in the late distal tubule.

At the bottom of Table III is listed the statistical analysis comparing the results of the Ringer's and the albumin studies. There was no difference in the results of any parameter in the control period in the two groups. In spite of comparable values for total kidney and nephron GFR in the two group, there was a markedly greater increase in absolute and fractional sodium excretion $(P<0.001$ for both values) during Ringer's. The proximal $\mathrm{TF} / \mathrm{P}_{\text {In }}$ ratio fell to a significantly lower level in the Ringer's group $(P<0.001)$ while absolute reabsorption decreased in this group but not during albumin infusion. Delivery of filtrate out of the proximal tubule was also greater in the Ringer's studies, 45.5 vs. $36.7 \mathrm{nl} / \mathrm{min}(P<0.001)$. A similar difference was also noted when the data was calculated in terms of the change in delivery from hydropenia to expansion $(P<$ $0.001)$. In spite of this greater increase in delivery out of the proximal tubule during Ringer's, there was no difference in the early or late distal $(T F / P)_{I n}$, $(\mathrm{TF} / \mathrm{P})_{\mathrm{Na}}$, or $(\mathrm{TF} / \mathrm{P})_{\mathrm{Na} / I n}$ ratio. These data indicate that the increased sodium delivery in the Ringer's group was counterbalanced by increased sodium reabsorption in Henle's loop leading to equal distal tubular delivery of sodium in the two groups.
In Fig. 3 is summarized the fractional reabsorptive data for the two groups. Fractional reabsorption of sodium in the proximal tubule decreased from approximately $60 \%$ to 32 and $41 \%$ in the Ringer's and albumin studies, respectively. This greater fall during Ringer's was statistically significant at the $P<0.005$ level. Fractional reabsorption in the loop of Henle and the distal tubule fell significantly in both groups to a similar extent during expansion. In contrast, fractional reabsorption in the collecting duct fell to a greater extent in the Ringer's group. During hydrogenia, fractional reabsorption was $96 \%$ and decreased to a mean of $31 \%$ for all experiments. In the albumin studies, fractional sodium reabsorption in the collecting duct fell to only $80 \%(P<$ 0.001 when compared with the Ringer's data).

In Fig. 4 is summarized the absolute reabsorptive data for all 16 Ringer's and 15 albumin studies. There was no significant difference in the amount of filtered sodium in the two groups. Absolute proximal tubular sodium reabsorption decreased from 3.63 to $3.06 \mathrm{neq} / \mathrm{min}$ during Ringer's $(P<0.025)$. In the albumin studies, absolute reabsorption was $3.74 \mathrm{neq} / \mathrm{min}$ during hydropenia and unchanged at $3.78 \mathrm{neq} / \mathrm{min}$ during expansion. This latter value was significantly greater than that found in the Ringer's studies $(P<0.05)$. Both absolute loop delivery and loop and distal tubular reabsorption rose in both groups when compared with hydropenia $(P<$ 0.001 for all values). Loop delivery was greater in the 


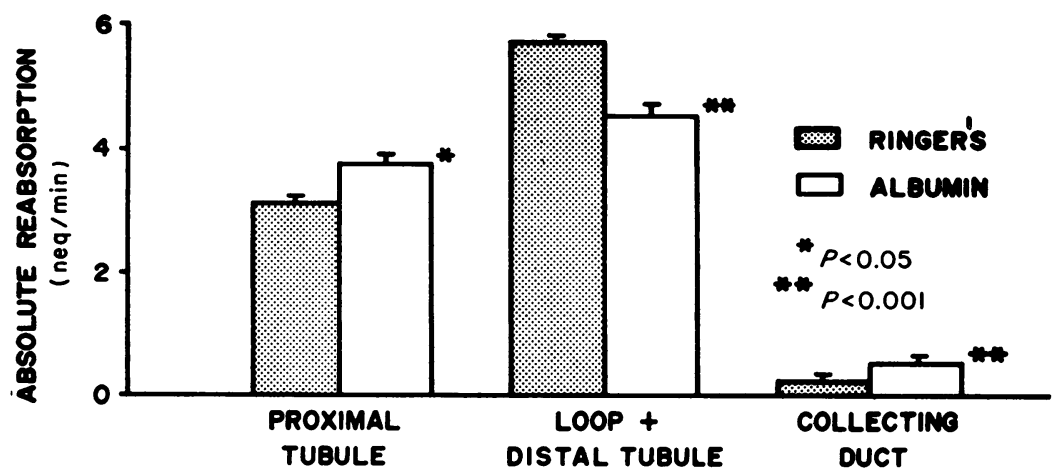

Figure 4 Segmental analysis of absolute sodium reabsorption during Ringer's and hyperoncotic albumin infusion.

Ringer's studies, 6.37 vs. $5.22 \mathrm{neq} / \mathrm{min}(P<0.001)$, but loop and distal tubular reabsorption was also increased in comparison to the albumin studies, 5.67 vs. $4.51 \mathrm{neq} /$ $\min (P<0.001)$, leading to no difference in the absolute amount of the $\mathrm{Na}$ remaining at the end of the distal tubule. In the group B studies, this data was further divided into loop and distal tubular reabsorption. In this group, absolute loop reabsorption was significantly greater in the Ringer's studies, 4.8 vs. $3.8 \mathrm{neq} / \mathrm{min}$ per nephron $(P<0.025)$. Absolute distal reabsorption was slightly greater in the Ringer's group, but this was not statistically significant. Absolute collecting duct reabsorption increased in both groups, but the rise was greater in the albumin studies, 0.55 vs. $0.21 \mathrm{neq} / \mathrm{min}$ $(P<0.001)$.

Microinjection studies. The results of these studies are summarized in Fig. 5. Mean sodium excretion from the right kidney was $9.2 \mu \mathrm{eq} / \mathrm{min}$ during Ringer's and $3.1 \mu \mathrm{e} / \mathrm{min}$ during albumin infusion $(P<0.001)$.
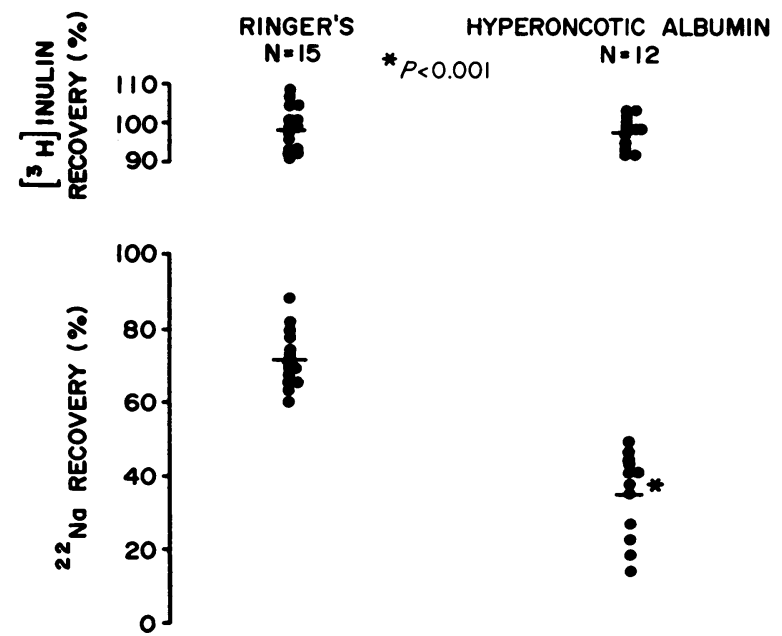

Figure 5 Summary of end distal ${ }^{22} \mathrm{Na}$ and $\left[{ }^{3} \mathrm{H}\right]$ inulin microinjection studies. $\left[{ }^{3} \mathrm{H}\right]$ inulin recovery in the Ringer's group ranged from 91 to $108 \%$ recovery with a mean of $98 \%$, while in the albumin injections the range was 92-102 with a mean recovery of $98 \%$. In contrast to the identical recovery of inulin in the two groups of studies, ${ }^{22} \mathrm{Na}$ recovery was markedly different. In the 15 Ringer's injections, the recovery ranged from 60 to $88 \%$ with a mean of $71 \%$. In the albumin studies recovery ranged from 15 to $48 \%$ with a mean of $34 \%$. This value was significantly different from the results of the Ringer's microinjections at the $P<0.001$ level.

\section{DISCUSSION}

In the present study, Ringer's solution caused a threefold greater increase in urinary sodium excretion when compared with equal intravascular volume expansion with hyperoncotic albumin infusion. This is quite similar to the findings of Howards, Davis, Knox, Wright, and Berliner in the $\operatorname{dog}(3)$ and Davidman, Alexander, Lalone, and Levinsky in the rat (16). In the previous studies, both saline and albumin depressed proximal tubular sodium reabsorption to a comparable extent in spite of the marked differences in urinary sodium excretion. From this it was assumed that the more distal portions of the nephron handled the increased sodium delivery differently in these two models. In the present study, we have also found that both infusions depress proximal tubular sodium reabsorption and increase delivery to Henle's loop. However, this effect was consistently greater in the Ringer's studies. In the study of Howards there was a suggestion that proximal tubular reabsorption was depressed to a greater extent during saline loading, but this was not statistically significant. However, Knox and associates, in a larger group of studies, have found a greater inhibition of proximal tubular sodium reabsorption during Ringer's infusion. ${ }^{2}$

\footnotetext{
${ }^{2}$ Knox, F. Unpublished observations.
} 
In evaluating the present data, there was some variation in tubular flow rate when recollection was done in the same tubule of a given animal (Fig. 1). However, with a coefficient of variation of $9 \%$, this would account for only a difference of $3.6 \mathrm{nl} / \mathrm{min}$ at a flow rate of 40 $\mathrm{nl} / \mathrm{min}$. This is considerably less than the mean difference in delivery out of the proximal tubule of $9 \mathrm{nl} / \mathrm{min}$ in the Ringer's and albumin studies. In addition, there may be variation from animal to animal. Although there was some overlap between the two groups, it can be noted from Tables II and III that delivery out of the proximal tubule was $40 \mathrm{nl} / \mathrm{min}$ or greater in 13 of 16 Ringer's studies and in only 4 of 15 experiments during albumin infusion. Similarly, there was little overlap in the $(\mathrm{TF} / \mathrm{P})_{\text {In }}$ data in the experimental periods of the two groups with the experimental $(\mathrm{TF} / \mathrm{P})_{\text {In }}$ vakue being 1.60 or less in 14 Ringer's studies and in only 4 albumin studies. Therefore, even considering micropuncture methodology and animal variability, this data seems clear enough to conclude that Ringer's infusion causes a greater depression of proximal tubular reabsorption.

The difference in proximal reabsorption during Ringer's and albumin infusion is in agreement with previous data demonstrating the role of peritubular capillary oncotic pressure on proximal tubular sodium reabsorption. Brenner and associates found in the rat that a decrease in peritubular capillary protein concentration depressed absolute $\mathrm{Na}$ reabsorption in the proximal tubule while the converse occurred when protein concentration was acutely increased (17). Daugherty, Ueki, Nicholas, and Brenner also found that Ringer's infusion depressed absolute reabsorption in the proximal tubule while plasma loading, which had only a minor effect on peritubular protein concentration, did not alter absolute $\mathrm{Na}$ reabsorption (18). Similarly, in the present study Ringer's infusion significantly decreased absolute reabsorption from 27 to $22 \mathrm{nl} / \mathrm{min}$, while hyperoncotic albumin had no effect. These latter collections were obtained at a time when serum protein concentration had returned to the control level and presumably had only slightly altered peritubular protein concentration (19). Therefore, the depressed absolute $\mathrm{Na}$ reabsorption during Ringer's infusion, presumably related to a fall in peritubular protein concentration, accounted for the major difference in delivery out of the proximal tubule when compared to expansion with hyperoncotic albumin.

In previous studies comparing expansion with Ringer's and albumin, distal tubular punctures were not obtained $(3,16)$. In the present study we found that in spite of the greater increase in sodium delivery in the Ringer's group, there was no discernable difference in the mean fractional or absolute delivery of sodium to either the early or late distal tubule in the two groups of studies (Tables II and III). As is shown in Fig. 4, ab-

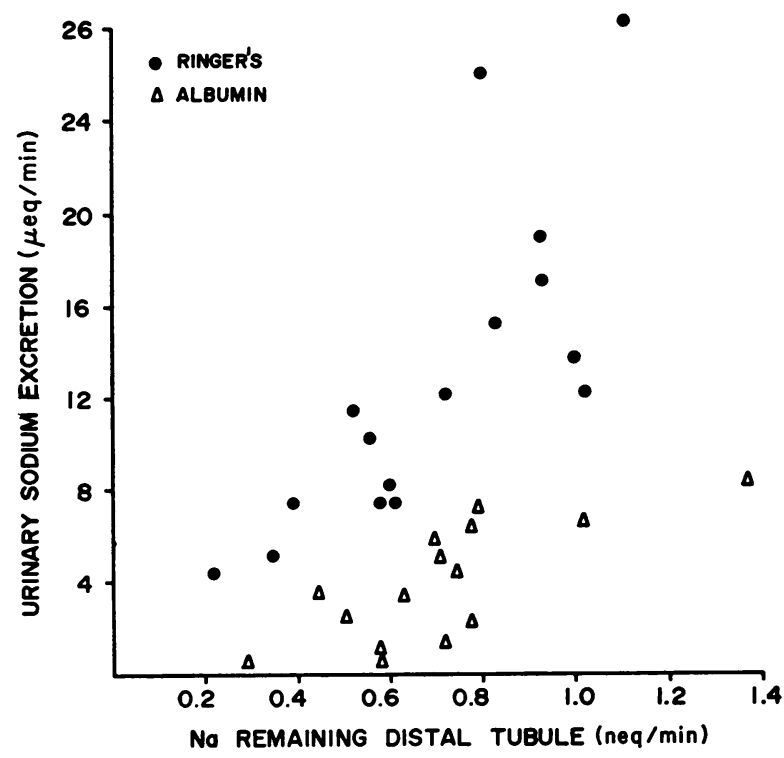

Figure 6 Comparison of end distal tubule sodium delivery vs. sodium excretion during Ringer's and hyperoncotic albumin infusion. The regression equations were $y=19.2 x$ $-0.73(r=0.78, P<0.001)$ for the Ringer's group and $y$ $=7.8 x-1.6(r=0.76, P<0.001)$ for the albumin studies. The slopes of these lines were significantly different $(P$ $<0.001$ ).

solute reabsorption of sodium in Henle's loop and the distal tubule was significantly greater in the Ringer's studies. In the group B studies, this was shown to be primarily due to enhanced loop transport of sodium. This data demonstrates that even at this markedly increased level of loop delivery, there was excellent glomerular tubular balance. The data in Fig. 6 lends further documentation to the accuracy of the end distal tubular collections. In this figure is plotted absolute sodium delivery per superficial nephron to the end of the distal tubule versus total urinary sodium excretion. There was a strong linear relationship between the amount of sodium remaining at the end of the distal tubule and urinary sodium excretion in both the Ringer's studies $(r=0.78, P<0.001)$ and the albumin experiments $(r=0.76, P<0.001)$. In addition, there was a marked difference in the linear regression lines of the two groups of experiments $(P<0.001)$. Therefore, at any given sodium delivery to the end of the distal tubule, urinary sodium excretion was greater in the Ringer's experiments.

There are at least two possible interpretations of this finding. First, since only distal tubules of superficial nephrons are sampled during micropuncture, while urinary sodium excretion is contributed by all nephrons, heterogeneity of nephron function could account for these findings. If nephron heterogeneity was responsible for the apparent difference in reabsorption in these two 
groups of studies, it would have to be assumed that either deep nephron sodium reabsorption was markedly inhibited during Ringer's infusion or enhanced in the albumin studies. Although the latter point has not been studied, Jamison and Lacy have evaluated juxtamedullary nephron sodium reabsorption during saline loading (20). They found little if any alteration in sodium reabsorption in juxtamedullary nephrons during saline loading, at least to the bend of Henle's loop, suggesting that the major contribution to the increase in urinary sodium excretion came from more superficial nephrons. Also, the findings in the present study of a linear relationship between end distal sodium delivery and urinary sodium excretion in both groups of experiments (Fig. 6) are strong evidence that end distal superficial nephron data is a representative index of overall nephron function in these models. If this is indeed correct, then it can be interpreted that collecting tubule and/or duct function are altered differently in these two models.

To further verify this point, end-distal tubule microinjections of ${ }^{22} \mathrm{Na}$ and $\left[{ }^{3} \mathrm{H}\right]$ inulin were performed (Fig. $5)$. Since the ${ }^{22} \mathrm{Na}$ was injected at the end of the distal tubule of superficial nephrons, and recovery of the isotope was from final urine, this technique would serve as an index of sodium flux along the length of the collecting duct. The data clearly demonstrate that the recovery of $\mathrm{Na}$ in final urine was markedly greater in the Ringer's group. This would suggest that in this group reabsorption along the collcting duct was less than during albumin infusion. Alternatively, it might be proposed that a greater deep nephron and end distal sodium delivery in the Ringer's group coupled with nonlinear transport characteristics in the collecting duct as a function of sodium load could give similar results. This interpretation seems unlikely because of the work of Jamison and Lacy mentioned previously (20). In addition, as would be predicted from the data in Fig. 6, fractional reabsorption of sodium in the collecting duct remained constant as delivery was increased in both groups, although the absolute value was set at a different level in the Ringer's and albumin studies (Table II and III). If collecting duct sodium transport was becoming progressively saturated as load increased, fractional reabsorption would be lower at the higher rates of delivery. Therefore, it seems more reasonable to interpret these results as further evidence that collecting duct sodium transport is indeed diminished during Ringer's infusion.

Studies by Gottschalk, Morel, and Mylle (12) and data from the present experiments showed no delayed excretion of ${ }^{22} \mathrm{Na}$, indicating that the recovery of ${ }^{22} \mathrm{Na}$ was independent of back diffusion of sodium from the interstitial compartment and primarily was a function of the change in mucosal to serosal transport and/or diffusion of sodium. That alteration in mucosal to serosal flux is the primary determinant of collecting duct transport in these two models is further suggested by the linear relationship between end distal sodium delivery and urinary sodium excretion in these two models (Fig. 6). If back diffusion of sodium was the major factor regulating net collecting duct sodium reabsorption, it would seem unlikely that this relationship would be present. Whether the ${ }^{22} \mathrm{Na}$ recovery can be taken as a quantitative index of unidirectional sodium transport or should only be utilized to compare fluxes in different models is not certain. In any case, the data clearly demonstrate that mucosal to serosal sodium transport along the collecting duct is lower in the Ringer's studies and presumably is the major factor accounting for the greater natriuresis in this model.

Diezi and associates have recently demonstrated that papillary collecting duct sodium transport rises as delivery is increased until very large rates of delivery are reached (21). In both the Ringer's and albumin studies absolute collecting duct reabsorption rose when compared with hydropenic values, but the rise was much greater at any delivery in the albumin experiments. The factors which control collecting duct transport have not been clearly delineated, but there are at least two possible explanations for the differences found in these two models. First, since aldosterone has been shown to affect collecting duct sodium transport (22), it is possible that differences in aldosterone secretion in these two models could explain the present results. However, both Ringer's (23) and albumin depress aldosterone secretory rate (24). Also, we have found no difference in potassium transport along the distal tubule or from the end of the distal tubule to the final urine during Ringer's and hyperoncotic albumin infusion. ${ }^{3}$ In addition, when compared with the present Ringer's studies, there was no difference in either free flow or microinjection data obtained when intravenous aldosterone was continuously administered during Ringer's infusion. ${ }^{3}$ Therefore, it seems quite unlikely that aldosterone could be responsible for the present findings.

Second, some humoral factor which alters collecting duct reabsorption may be released during volume expansion with Ringer's but not albumin. Since both Ringer's and albumin expand intravascular volume, while only Ringer's increases interstitial volume, such a humoral factor may be released primarily in response to expansion of this latter compartment.

In summary, the present studies demonstrate the importance of sodium reabsorption in the collecting duct as a major determinant of urinary sodium excretion. Although this is not meant to imply that alterations in proximal reabsorption do not alter sodium excretion, it

${ }^{3}$ Stein, J. H., R. W. Osgood, and T. F. Ferris. Unpublished observations. 
seems clear from this data that delivery out of the proximal tubule is not the sole determinant of the quantity of sodium in the final urine.

\section{ACKNOWLEDGMENTS}

We wish to acknowledge the excellent technical assistance of Elena Boelin, Ellen Grimes, Pat Hill, Linda Howe, and Cindy Smail, and the secretarial expertise of Jo Ann Goodman.

These studies were supported in part by National Institutes of Health grants 2 RO1 AM 13524-04, 5 RO1 HL13653 , and 1 TO1 HL05975-01, and by a grant from the Central Ohio Heart Association.

\section{REFERENCES}

1. Dirks, J. H., W. J. Cirksena, and R. W. Berliner. 1965. The effect of saline infusion on sodium reabsorption by the proximal tubule of the dog. J. Clin. Invest. 44:1160.

2. Cortney, M. A., M. Mylle, W. E. Lassiter, and C. W. Gottschalk. 1965. Renal tubular transport of water, solute and PAH in rats loaded with isotonic saline. Am. J. Physiol. 209: 1199.

3. Howards, S. S., B. B. Davis, F. G. Knox, F. S. Wright, and R. W. Berliner. 1968. Depression of fractional sodium reabsorption by the proximal tubule of the dog without sodium diuresis. J. Clin. Invest. 47: 1561.

4. Agus, Z. S., J. B. Puschett, D. Senesky, and M. Goldberg. 1971. Mode of action of parathyroid hormone and cyclic adenosine $3^{\prime}, 5^{\prime}$ monophosphate on renal tubular phosphate reabsorption in the dog. J. Clin. Invest. 50: 617 .

5. Burke, T. J., R. R. Robinson, and J. R. Clapp. 1971. Effect of arterial hematocrit on sodium reabsorption by the proximal tubule. Am. J. Physiol. 220: 1536.

6. Schneider, E. G., T. P. Dresser, R. E. Lynch, and F. G. Knox. 1971. Sodium reabsorption by proximal tubule of dogs with experimental heart failure. Am. J. Physiol. 220: 952.

7. Auld, R. B., E. A. Alexander, and N. G. Levinsky. 1971. Proximal tubular function in dogs with thoracic caval constriction. J. Clin. Invest. 50: 2150.

8. Levy, M. 1972. Effects of acute volume expansion and altered hemodynamics on renal tubular function in chronic caval dogs. J. Clin. Invest. 51: 922.

9. Cortell, S., M. Davidman, F. J. Gennari, and W. B. Schwartz. 1972. Catheter size as a determinant of outflow resistance and intrarenal pressure. Am. J. Physiol. 223: 910.

10. Malnic, G., R. M. Klose, and G. Giebisch. 1966. Micropuncture study of distal tubular potassium and sodium transport in rat nephron. Am. J. Physiol. 211: 529.
11. Cortney, M. A. 1969. Renal tubular transfer of water and electrolytes in adrenalectomized rats. Am. J. Physiol. 216: 589 .

12. Gottschalk, C. W., F. Morel, and M. Mylle. 1965. Tracer microinjection studies of renal tubular permeability. Am.J. Physiol. 209: 173.

13. Führ, J., J. Kaczmarczyk, and C. D. Krüttgen. 1955. Eine einfache colorimetrische methode zur inulinbestimmung für nieren-clearance-untersuchungen bei Stoffwechselgesunden und Diabetikern. Klin. Wochschr. 33: 729.

14. Vurek, G. G., and S. E. Pegram. 1966. Fluorometric method for the determination of nanogram quantities of inulin. Anal. Biochem. 16: 409.

15. Lowry, O. H., N. J. Rosebrough, A. L. Farr, and R. J. Randall. 1951. Protein measurement with the Folin phenol reagent. J. Biol. Chem. 193: 265.

16. Davidman, M., E. Alexander, R. Lalone, and N. Levinsky. 1972. Nephron function during volume expansion in the rat. Am. J. Physiol. 223: 188.

17. Brenner, B. M., K. H. Falchuk, R. I. Keimowitz, and R. W. Berliner. 1969. The relationship between peritublar capillary protein concentration and fluid reabsorption by the renal proximal tubule. J. Clin. Invest. 48: 1519.

18. Daugharty, T. M., I. F. Ueki, D. P. Nicholas, and B. M. Brenner. 1972. Comparative renal effects of isoncotic and colloid-free volume expansion in the rat. Am. J. Physiol. 222: 225.

19. Knox, F. G., L. R. Willis, J. W. Strandhoy, E. G. Schneider, L. G. Navar, and C. E. Ott. 1972. Role of peritubule Starling forces in proximal reabsorption following albumin infusion. Am. J. Physiol. 223: 741.

20. Jamison, R. L., and F. B. Lacy. 1971. Effect of saline infusion on superficial and juxtamedullary nephrons in the rat. Am. J. Physiol. 221: 690 .

21. Diezi, J., P. Michoud, J. Aceves, and G. Giebisch. 1973. Micropuncture study of electrolyte transport across papillary collecting duct of the rat. Am. J. Physiol. 224: 623 .

22. Uhlich, E., C. A. Baldarmus, and K. J. Ullrich. 1969. Einfluss von Aldosteron auf den Natriumtransport in den Sammelrohren der Säugetierniere. Arch. Gesamte. Physiol. 308: 111 .

23. Williams, G. H., M. L. Tuck, L. I. Rose, R. G. Dluhy, and R. H. Underwood. 1972. Studies of the control of plasma aldosterone concentration in normal man. III. Response to sodium chloride infusion. J. Clin. Invest. $51: 2645$.

24. Goodman, A. D., A. H. Vagnucci, and P. M. Hartroft. 1969. Pathogenesis of Bartter's Syndrome. N. Engl. J. Med. $281: 1435$. 